\title{
The role of phase separation for self-organized surface pattern formation by ion beam erosion and metal atom co-deposition
}

\author{
H. Hofsäss • K. Zhang • A. Pape • O. Bobes • \\ M. Brötzmann
}

Received: 30 July 2012 / Accepted: 14 September 2012 / Published online: 3 October 2012

(c) The Author(s) 2012. This article is published with open access at Springerlink.com

\begin{abstract}
We investigate the ripple pattern formation on $\mathrm{Si}$ surfaces at room temperature during normal incidence ion beam erosion under simultaneous deposition of different metallic co-deposited surfactant atoms. The co-deposition of small amounts of metallic atoms, in particular Fe and Mo, is known to have a tremendous impact on the evolution of nanoscale surface patterns on Si. In previous work on ion erosion of Si during co-deposition of $\mathrm{Fe}$ atoms, we proposed that chemical interactions between $\mathrm{Fe}$ and $\mathrm{Si}$ atoms of the steady-state mixed $\mathrm{Fe}_{x} \mathrm{Si}$ surface layer formed during ion beam erosion is a dominant driving force for self-organized pattern formation. In particular, we provided experimental evidence for the formation of amorphous iron disilicide. To confirm and generalize such chemical effects on the pattern formation, in particular the tendency for phase separation, we have now irradiated Si surfaces with normal incidence $5 \mathrm{keV} \mathrm{Xe}$ ions under simultaneous gracing incidence co-deposition of $\mathrm{Fe}, \mathrm{Ni}, \mathrm{Cu}, \mathrm{Mo}, \mathrm{W}, \mathrm{Pt}$, and $\mathrm{Au}$ surfactant atoms. The selected metals in the two groups $(\mathrm{Fe}, \mathrm{Ni}, \mathrm{Cu})$ and $(\mathrm{W}, \mathrm{Pt}, \mathrm{Au})$ are very similar regarding their collision cascade behavior, but strongly differ regarding their tendency to silicide formation. We find pronounced ripple pattern formation only for those co deposited metals $(\mathrm{Fe}, \mathrm{Mo}, \mathrm{Ni}, \mathrm{W}$, and $\mathrm{Pt}$ ), which are prone to the formation of mono and disilicides. In contrast, for $\mathrm{Cu}$ and $\mathrm{Au}$ co-deposition the surface remains very flat, even after irradiation at high ion fluence. Because of the very different behavior of $\mathrm{Cu}$ compared to $\mathrm{Fe}, \mathrm{Ni}$ and $\mathrm{Au}$ compared to $\mathrm{W}, \mathrm{Pt}$, phase separation toward amorphous metal silicide phases is seen as the relevant pro-
\end{abstract}

H. Hofsäss ( $\varangle) \cdot$ K. Zhang · A. Pape · O. Bobes · M. Brötzmann II. Institute of Physics, Georg-August University Göttingen, Friedrich-Hund-Platz 1, 37077 Göttingen, Germany

e-mail: hans.hofsaess@phys.uni-goettingen.de

Fax: +49-551-394493 cess for the pattern formation on $\mathrm{Si}$ in the case of $\mathrm{Fe}, \mathrm{Mo}$, $\mathrm{Ni}, \mathrm{W}$, and Pt co-deposition.

\section{Introduction}

The simultaneous co-deposition of small amounts of atoms during ion beam erosion of surfaces has a tremendous influence on the self-organized nano pattern formation [1-6].

Several groups have recently demonstrated that in particular co-deposition of Fe and Mo surfactant atoms at room temperature induce pronounced dot and ripple patterns on Si substrates, even during normal and near normal ion incidence sputter erosion [2-4, 6-8]. Without co-deposition, the surface remains very uniform and flat $[2,7,9]$. Our group has previously investigated surfactant driven pattern formation on $\mathrm{Si}$ with oblique incidence $\mathrm{Fe}$ co-deposition and normal incidence noble gas ion irradiation [2]. We introduced a pattern formation scenario based on initial chemical effects and phase separation processes. In a recent work, we provide experimental evidence for the formation of an amorphous iron discilicide layer during surfactant sputtering, which results in a flat surface if the stoichiometry approaches $\mathrm{FeSi}_{2}$ [18]. In the present work, we provide new experimental studies using the same experimental setup, but carried out with a number of different co-deposited metal atoms. In this way, we are able to generalize the validity of our pattern formation scenario and provide evidence that in particular the co-deposition of metals prone to disilicide formation results in pronounced dot and ripple patterns on Si substrates.

Cone formation or relief pattern formation on various substrates during sputter erosion with accidentally or intentionally co-deposition of metals atoms has been known for many years [10-16]. In several of these experiments, $\mathrm{Si}$ was used as a substrate material and the substrates were 
kept at high temperatures of $400-650^{\circ}[14,16,17]$. Enhanced atomic diffusion in combination with instantaneous silicide formation lead to the formation of metal silicide seed droplets on the surface preventing the underneath substrate material from being sputtered. As a result, arrays of cones with a height of several $\mu \mathrm{m}$ are formed.

Ion beam erosion of $\mathrm{Si}$ or amorphous carbon under similar conditions, but performed at room temperature, also results in a variety of patterns such as relief patterns, holes, dots, chains of dots, or ripples [1-4, 6, 18-20]. Typically, the pattern height only reaches several $\mathrm{nm}$ and the lateral characteristic length scale is in the order of $100 \mathrm{~nm}$. Furthermore, after irradiation an amorphous mixed surface layer has formed [2, 4-6, 19, 20].

It was emphasized by our group that co-deposited atoms act as surfactants and typically cause the formation of a steady-state compound surface layer, which strongly affects the pattern formation process [1]. In particular, Fe and Mo surfactants induce pronounced dot and ripple patterns on Si substrates even during near normal ion incidence sputter erosion [2-4, 6-8]. Without co-deposition, the surface of $\mathrm{Si}$ remains very uniform and flat for ion beam erosion at normal and near normal ion incidence, even for incidence angles up to about $45^{\circ}$ with respect to the surface normal $[2,7,9]$. This behavior can be explained by the Carter-Vishnyakov (CV) effect describing the collision cascade mass transport and redistribution [21, 22]. For ion incidence angles up to $45^{\circ}$, the CV effect would stabilize the surface in projected beam direction, and thus suppress the formation of parallel ripples (ripple wave vector parallel to the projected ion beam direction).

In the case of metal co-deposition and normal ion incidence, the manifold of patterns (holes, dots, chains of dots, or ripples) and also the pattern height strongly depend on the steady-state surfactant area coverage and the ion fluence [2]. It was also observed that the direction of incidence of co-deposited surfactant atoms determines the pattern orientation and also the shape of the patterns [2-4]. Structural and elemental analysis using transmission electron microscopy (TEM) and Rutherford backscattering spectroscopy (RBS) of patterned surfaces created with Fe surfactants reveal a few $\mathrm{nm}$ thick amorphous $\mathrm{Fe}_{x} \mathrm{Si}$ surface layer with laterally varying $\mathrm{Fe}$ concentration between a few at. $\%$ and in excess of 20 at.\%, with the highest $\mathrm{Fe}$ concentration in the regions of dots and ripple ridges [2, 4]. The thickness of the amorphous mixed layer correlates with the projected ion range.

In the mean time, several theoretical studies have also considered co-deposition of surfactant atoms during sputter erosion as an essential parameter for pattern formation. Kree et al. have first presented a continuum theory as well as a Mont Carlo simulation taking into account surfactant sputtering [23, 24]. The Monte Carlo simulation is based on a solid-on-solid model with two types of atoms A and B with different but interconnected erosion and diffusion parameters. The continuum model considers surfactants by a varying surface density, different diffusion current densities and individual sputter yields depending on the local surface density. Depending on the behavior of A and B atoms, compositional modulations of surfactants, smoothing of surfaces, or novel pattern generation-like dot patterns can occur. Bradley presented a continuum theory for nanodots and cones generated during ion erosion with concurrent normal incidence impurity deposition [25]. The mechanisms included are an impurity concentration profile extending into the depth of the substrate, atomic species dependent surface diffusion, transport due to capillarity, preferential sputtering as well as momentum transfer from atomic collisions. It is shown that even immobile impurities may destabilize a surface leading to a disordered arrangement of mounds on the surface if a certain critical impurity flux is exceeded. In a recent theoretical study, Bradley considered ion beam erosion under the simultaneous off-angle co-deposition of atoms and introduced a model for pattern formation, which does not require curvature dependent sputtering and the CV effect [26]. The model takes into account concentration and local angle dependent erosion rates of two components A (surfactant) and B (substrate) as well as atomic currents due to viscous flow. Thermal diffusion as well as chemical interactions is neglected. It is shown that under certain conditions a surface will become unstable and a ripple pattern will occur. For normal ion incidence the model predicts the surface to be unstable if the zero degree substrate sputter yield is higher compared to the sputter yield of a co-deposited species (Eq. (32) in [26]), i.e., the substrate is preferentially sputtered. Furthermore, the model predicts the maximum ripple wavelength to scale inversely to the ratio of co-deposition flux to ion flux $I_{d} / I_{i o n}$ and the sine of the co-deposition angle $\sin \left(\theta_{d}\right)$ (Eq. (33) in [26]). In the systems investigated in the following, as most other experimental data on sputter erosion under co-deposition, the substrate sputter yield is much smaller than the sputter yield for co-deposited species by a factor 3-6, and the model would not predict pattern formation. Also, at low co-deposition flux, the experiments show dot patterns rather than long wavelength ripple patterns [2, 4].

Up to now, theoretical models do not take into account the chemical interaction of the components of a binary compound, especially the tendency of phase separation into phases of well-defined stoichiometry. On the other hand, our group has recently proposed a scenario for surfactant driven pattern formation on $\mathrm{Si}$ with $\mathrm{Fe}$ co-deposition at normal ion incidence, which is based on initial phase separation processes, followed by composition dependent erosion and eventually preferential deposition of surfactant atoms and shadowing effects [2].

For the case of Fe co-deposition, the evolution of ripple patterns as a function of $\mathrm{Fe}$ coverage was recently studied 
$[17,18]$. In our recent study, we observed a sharp transition from a rippled surface to a flat surface within a narrow regime of the steady state Fe surface coverage around $1.8 \times 10^{16} \mathrm{Fe} / \mathrm{cm}^{2}$, where the composition of the $10 \mathrm{~nm}$ thick mixed $\mathrm{Fe}-\mathrm{Si}$ surface layer reaches the stoichiometry of $\mathrm{FeSi}_{2}$ [18]. Phase separation toward amorphous iron silicide was proposed as the major contribution for the pattern formation at lower Fe coverage and the sharp transition from ripple patterns to a flat surface. Further experimental evidence supporting the initial phase separation process for the $\mathrm{Fe} / \mathrm{Si}$ system and a generalization to other metal/Si systems is still required and shall be provided with the present work.

Ion induced phase separation is an essential process for the multilayer formation of ion beam deposited metal carbon nanocomposite films [27-29]. Ion-induced phase separation has been observed as volume effect, e.g., in binary metal alloys [30-32] and was attributed to metal nanocrystal formation at $\mathrm{Si} / \mathrm{SiO}_{2}$ interfaces [33], in Pt/C layered films [34], ion irradiated $\mathrm{C} / \mathrm{Cr}$ coatings [35], and ion irradiated $\mathrm{GeO}_{x}$ films [36]. Compositional patterning of metallic alloys due to phase separation was studied with kinetic Monte Carlo simulations $[30,37,38]$. The role of phase separation was also emphasized by kinetic Monte Carlo simulations of Au-silica nanocomposite film growth [39]. Phase separation also occurs during cone formation by ion beam sputter erosion of $\mathrm{Si}$ and seeding with Mo or Ni, usually performed at high temperatures. The cones typically have a highly inhomogeneous composition ranging from pure $\mathrm{Si}$ over $\mathrm{Mo}_{3} \mathrm{Si}_{2}, \mathrm{MoSi}_{2}$, or $\mathrm{Ni}_{3} \mathrm{Si}_{2}$ silicides to pure metal nanoparticles [14, 40, 41]. In particular, silicide tips are formed on top of the cones. Pronounced phase separation also takes place in ion beam irradiation induced cone formation on compound semiconductors like InSb or GaSb [42, 43]. Usually, metal silicides are considered as crystalline phases, however, amorphous $\mathrm{Fe}$ disilicide has attracted attention as a semiconducting material with a band gap of $0.9 \mathrm{eV}$ with potential applications as photovoltaic material [44-46]. The identification of amorphous metal silicides can be done on the basis of X-ray photoelectron spectroscopy (XPS) or an analysis of atom pair distribution function measured with electron diffraction [18, 47-49].

The aim of the present study is to provide new experimental data on ion-induced pattern formation on $\mathrm{Si}$ with codeposition of different metal atoms species. The metal atoms are chosen based on their binary phase diagram with Si. Furthermore, we chose normal ion incidence, so that the ion irradiation itself does not cause pattern formation. This allows us to investigate the role of phase separation processes on the pattern formation. We investigate pattern formation on Si substrates for normal incidence $5 \mathrm{keV} \mathrm{Xe}$ ion irradiation at room temperature under simultaneous oblique angle co-deposition of $\mathrm{Fe}, \mathrm{Ni}, \mathrm{Cu}, \mathrm{Mo}, \mathrm{W}, \mathrm{Pt}$, or $\mathrm{Au}$ surfactant atoms using the same experimental setup used for our previous work [2] on Fe co-deposition onto Si. The important

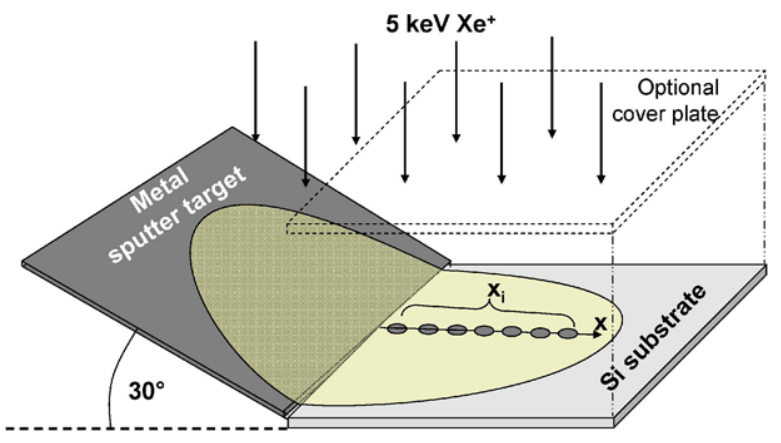

Fig. 1 Schematic illustration of the experimental setup. Si is irradiated with $5 \mathrm{keV} \mathrm{Xe}$ ions at normal ion incidence. Metal co-deposition originates from adjacent metal foil targets inclined at $30^{\circ}$. The beam diameter is $12 \mathrm{~mm}$. To measure the local metal atom deposition rate, the $\mathrm{Si}$ substrate can be blocked from the ion beam with an optional cover plate. The positions $x_{i}$ indicates different analysis positions for AFM and RBS measurements

role of phase separation on the pattern formation becomes obvious in particular for $\mathrm{Fe}, \mathrm{Ni}, \mathrm{Mo}$, and $\mathrm{W}$, where a metal disilicide phase exists in the binary phase diagram with $\mathrm{Si}$.

\section{Experimental}

Single-crystalline Si (100) substrates of size $7 \times 10 \mathrm{~mm}$ and adjacent inclined metal targets were irradiated simultaneously with $5 \mathrm{keV} \mathrm{Xe}^{+}$ions at room temperature under high vacuum conditions of $2 \times 10^{-6} \mathrm{~Pa}$. The parallel ion beam of $12 \mathrm{~mm}$ diameter was provided by a low-energy Colutron ${ }^{\circledR}$ ion beam system with Wien-filter mass selection and a beam sweep system [50]. The ion flux was about $0.6 \mu \mathrm{A} / \mathrm{cm}^{2}$ and the ion fluence was varied between $5 \times 10^{16} \mathrm{Xe} / \mathrm{cm}^{2}$ up to $5 \times 10^{17} \mathrm{Xe} / \mathrm{cm}^{2}$. The ion beam is incident along the normal direction of the Si surface. Prior to irradiation, the $\mathrm{Si}$ samples were cleaned sequentially in an ultrasonic bath with acetone and methanol.

The metal targets for co-deposition were high purity foils ( $\mathrm{Fe}, \mathrm{Ni}, \mathrm{Cu}, \mathrm{Mo}, \mathrm{W}, \mathrm{Pt}$, and $\mathrm{Au}$ ) positioned adjacent to the Si substrate at inclination angles of $30^{\circ}$ of its surface normal relative to the ion beam direction. Half of the ion-beam irradiated the Si-substrate, while the other half simultaneously irradiated the metal foil target (Fig. 1). Sputtered metal atoms are deposited onto the Si substrate with an incidence angle distribution of $60-90^{\circ}$ with respect to the surface normal and within about $\pm 45^{\circ}$ azimuth angles. In this geometrical arrangement, a fraction of sputtered metal atoms are deposited onto the Si substrate. The metal deposition flux across the $\mathrm{Si}$ substrate decreases with increasing distance from the sputter target. In this way, a gradient in the steadystate metal coverage is established and allows one to study the erosion effects as a function of the metal surfactant coverage. 
The simultaneous irradiation of sputter target and substrate with a broad parallel ion beam couples the local codeposition flux and the ion flux. For a given position on the substrate, this flux ratio is constant, irrespective of possible fluctuations of the ion beam current. This is a great advantage compared to a setup with a decoupled ion beam source and co-deposition source, which would require a perfect stabilization of both sources during a rather long exposure time. Moreover, with the coupled substrate-target system, the local flux ratio can easily be measured. This is done by blocking the part of the ion beam hitting the substrate with a cover plate (indicated in Fig. 1 with dashed lines). The substrate is then not exposed to ions and is just coated with sputtered metal atoms. The local area density of the deposited metal film can easily be measured with Rutherford backscattering. Together with the ion fluence used, we quantitatively obtain the local ion-to-metal flux ratio at different points on the substrate for a given geometrical arrangement of substrate and sputter target. A small error occurs due to back and forth sputtering between substrate and sputter target. However, knowledge of the exact value of the local flux ratio is not necessary for further analysis. It is much more important to keep the local flux ratio stable throughout the duration of the ion irradiation and to measure the local steady state Fecoverage afterward using Rutherford backscattering.

The issue of ions reflected (or better backscattered) from the sputter target is sometimes brought to attention. The fraction, the energies, and the angular distribution of backscattered ions can be calculated with SDTrimSP [51]. Considering our setup with an inclination angle of the sputter target of $30^{\circ}$, the total fraction of backscattered $5 \mathrm{keV}$ $\mathrm{Xe}$ ions varies between $0.3-0.7 \%$ for $\mathrm{Fe}, \mathrm{Ni}$, and $\mathrm{Cu}, 2 \%$ for Mo and 10-11\% for W, Pt, and Au. About $50 \%$ of the backscattered ions have energies below $250 \mathrm{eV}$. The angular distribution of backscattered ions is rather broad and most backscattered ions do not reach the adjacent Si substrate. In the case of backscattering from $\mathrm{Au}$, we estimate a fraction of about $1 \%$ of the backscattered ions emitted toward the area of the Si substrate exposed to the primary ions. Therefore, the flux of low energy backscattered Xe ions is less than $10^{-3}$ of the primary flux for the case of an Au sputter target. For lighter targets, the flux is even much smaller. An influence due to backscattered ions is therefore negligible.

Values for ion ranges, straggling and sputter yields were calculated using SDTrimSP [51]. The mean ion range of $5 \mathrm{keV} \mathrm{Xe}$ ions on $\mathrm{Si}$ is $9 \pm 2 \mathrm{~nm}$. Also, the damage distribution extends to about $10 \mathrm{~nm}$ below the surface. Assuming a mixed layer of $10 \mathrm{~nm}$ thickness with metal coverage of $5-8 \times 10^{15}$ at. $/ \mathrm{cm}^{2}$, the metal concentration in such a layer is about 10-20 at.\%. The calculated sputter yield for $5 \mathrm{keV}$ $\mathrm{Xe}$ and pure $\mathrm{Si}$ is $\mathrm{Y}_{\mathrm{Si}}\left(0^{\circ}\right)=1.75$ and may rise due to sputter yield amplification [52] to values up to $\mathrm{Y}=3$ if heavy metal atoms are present in the collision cascade volume with the estimated concentration.
The surface topography of the sputter eroded samples were analyzed by atomic force microscopy (AFM) in contact mode using a Nanosurf microscope and Si cantilevers from NanoAndMore $\mathrm{GmBH}$ with mean tip radius $<7 \mathrm{~nm}$. AFM measurements were done using the Nanosurf Easyscan software. For topography analysis as well as statistical analysis and Fourier transformations, we used the open source software Gwyddion [53]. The average metal coverage on different spots of the $\mathrm{Si}$ samples was quantitatively determined by Rutherford-backscattering spectroscopy (RBS) at the Göttingen $500 \mathrm{keV}$ ion accelerator [54] with $900 \mathrm{keV} \mathrm{He}^{++}$-ions and a beam spot of $1 \mathrm{~mm} \mathrm{di-}$ ameter. High resolution RBS analyses of the concentrationdepth profiles of metal surfactants were done with a $450 \mathrm{keV}$ $\mathrm{He}^{+}$ion beam with $0.5 \mathrm{~mm}$ diameter. $\mathrm{He}^{+}$ions backscattered at $150^{\circ}$ were energy-analyzed using an electrostatic cylindrical analyzer providing a near-surface depth resolution of less than $2 \mathrm{~nm}$ [55].

The microstructure of the samples was analyzed with Transmission Electron Microscopy (TEM) using a $200 \mathrm{kV}$ Philips CM 200-UT microscope. The scanning mode of the microscope allows the measurement of EDX line scans along a defined path. TEM sample were prepared with a focused ion beam (FIB) system. This technique requires deposition of a $\mathrm{Pt}-\mathrm{C}$ cover layer. In order to spatially separate the Si-metal surface from this Pt layer in the TEM images, the samples were coated with an amorphous carbon capping layer prior to the FIB preparation. The capping layer was deposited by ion beam deposition [56].

\section{Results}

A survey of AFM images of a Si substrate sputtered with $5 \mathrm{keV} \mathrm{Xe}$ ions and Mo surfactant co-deposition is shown in Fig. 2. From bottom to top row, the images are obtained after irradiation with increasing ion fluence of $5 \times 10^{16}$ up to $5 \times 10^{17} \mathrm{Xe} / \mathrm{cm}^{2}$. From the left to the right column, the analysis position $x_{i}$ (see Fig. 1) decreases, i.e., gets closer to the sputter target. Therefore, the local Mo atom flux increases from left to right. The ratio of deposited Mo atoms per incident Xe ion varies between $3.4 \%$ and $8.1 \%$ and was measured for each position with RBS. For each AFM image, we have also indicated the steady state Mo coverage as measured with RBS. Taking the upper right image as an example, $0.081 \times 5 \times 10^{17}=4.05 \times 10^{16} \mathrm{Mo} / \mathrm{cm}^{2}$ were deposited during the ion irradiation. Most of these deposited atoms are sputtered of and only $13 \%$ or $5.4 \times 10^{15} \mathrm{Mo} / \mathrm{cm}^{2}$ remain as steady state coverage. The survey clearly reveals a region of low ion fluence and low Mo coverage where no pattern formation is observed. Above certain limits (indicated as thick line separating the AFM images), a granular irregular pattern of dots is generated. A similar pattern was observed 
Fig. 2 AFM images of a $\mathrm{Si}$ surface sputtered with $5 \mathrm{keV} \mathrm{Xe}$ ions at normal ion incidence and co-deposition of Mo atoms. The images represent erosion with different ion fluence and different Mo/Xe deposition ratio. The steady-state coverage of Mo as measured with RBS is indicated in each image

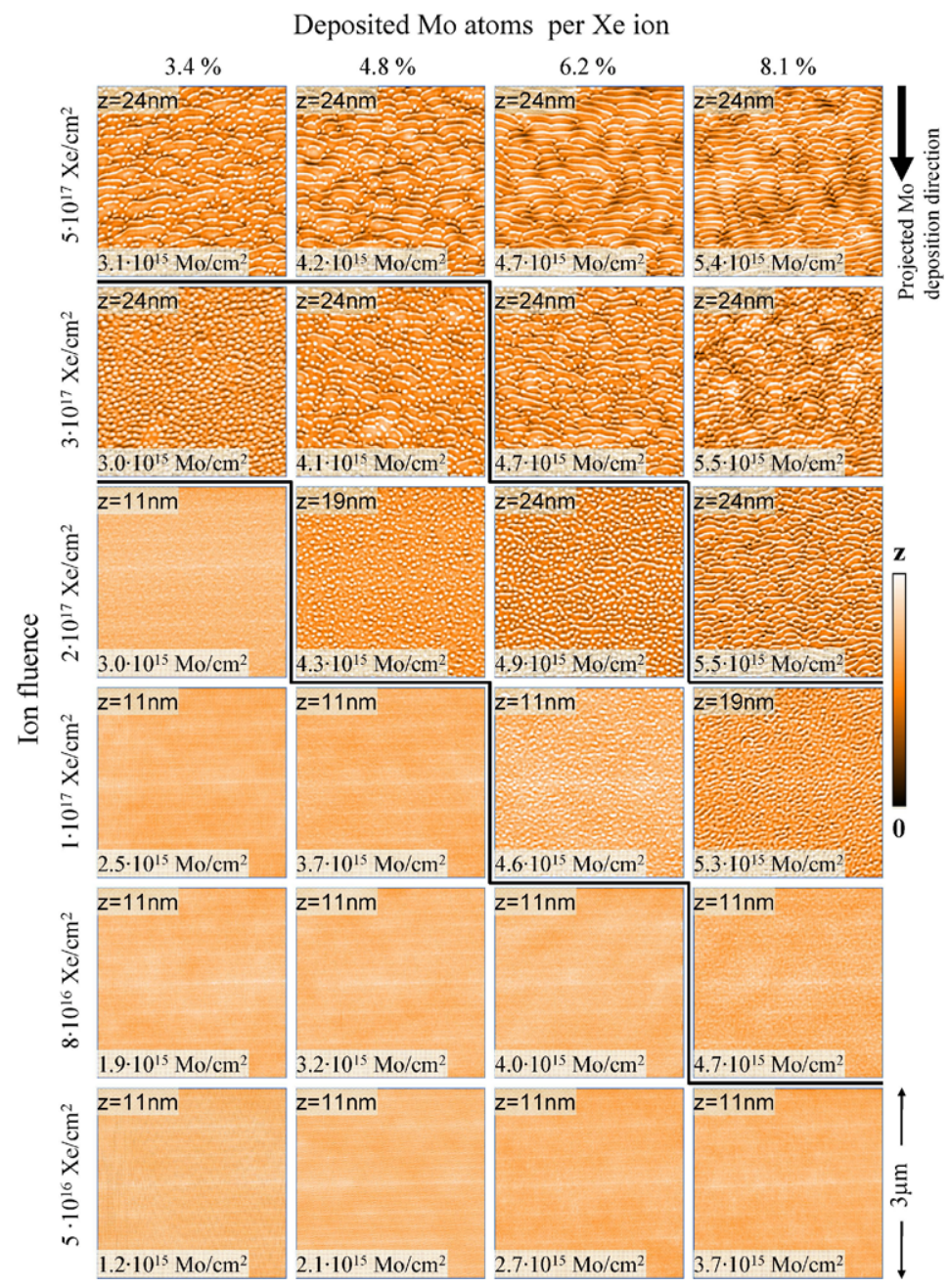

for $500 \mathrm{eV}$ Ar perpendicular ion irradiation and Mo seeding [16]. The dots grow in height with increasing ion fluence, as can be seen from the height scale values shown in Fig. 2. The same behavior was also found for the $\mathrm{Fe}-\mathrm{Si}$ system [2]. With further increased ion fluence and steady-state Mo coverage, the dots eventually evolve into ripple patterns. The transition region is also indicated by a thick line separating the AFM images. The orientation of the ripples is parallel to the projected direction of Mo co-deposition (wave vector parallel to the projected direction of co-deposition). This behavior is almost identical to the one observed for co-deposition of $\mathrm{Fe}$ surfactants during normal ion incidence $\mathrm{Si}$ erosion [2]. A TEM analysis of the cross section through a ripple segment is shown in Fig. 3. In analogy to our previous results for Fe surfactants [2], an amorphous Mo-Si layer is formed with a thickness corresponding to the $\mathrm{Xe}$ ion range. The Mo concentration is highest in the ripple ridges. A similar TEM analysis made of a dot pattern (not shown) also reveals a higher Mo concentration in the dot regions. A lateral inhomogeneous $\mathrm{Fe}$ and Mo concentration in a surface layer with dot patterns on Si was also reported earlier [6].
Figure 4 shows a compilation of AFM images of surface patterns obtained for either $\mathrm{Fe}, \mathrm{Ni}, \mathrm{Mo}, \mathrm{W}$, or Pt codeposition and for an ion fluence of $5 \times 10^{17} / \mathrm{cm}^{2}$. For each metal species, three images with different surface coverage in the range $10^{15}-10^{16}$ atoms $/ \mathrm{cm}^{2}$ are shown. Except for $\mathrm{Pt}$ co-deposition, pronounced dot or ripple patterns are seen in all cases. The pattern type depends on the surface coverage and evolves from dot patterns or chains of dots at lower coverage to ripple patterns at higher coverage within a rather narrow regime. Increasing the metal coverage by less than a factor 2 from $3 \times 10^{15}$ to $5 \times 10^{15}$ atoms $/ \mathrm{cm}^{2}$ changes, the pattern from dots to ripples for $\mathrm{Fe}, \mathrm{Mo}$, and $\mathrm{W}$ surfactants. For Ni surfactants, the transition occurs at somewhat higher coverage between $5 \times 10^{15}$ to $8 \times 10^{15} \mathrm{Ni} / \mathrm{cm}^{2}$. Pattern formation on Si with Pt surfactants starts at a rather high coverage of about $7 \times 10^{15} \mathrm{Pt} / \mathrm{cm}^{2}$ and immediately results in a weak ripple pattern rather than dots. The ripple wavelength in all cases is in the range 100-150 nm. For Fe, Ni, Mo, and $\mathrm{W}$, the ripples have an asymmetric triangular shape and the amplitudes are between 10 and $15 \mathrm{~nm}$. Pt surfactants create an approximately sinusoidal ripple profile with amplitude of about $7 \mathrm{~nm}$. 

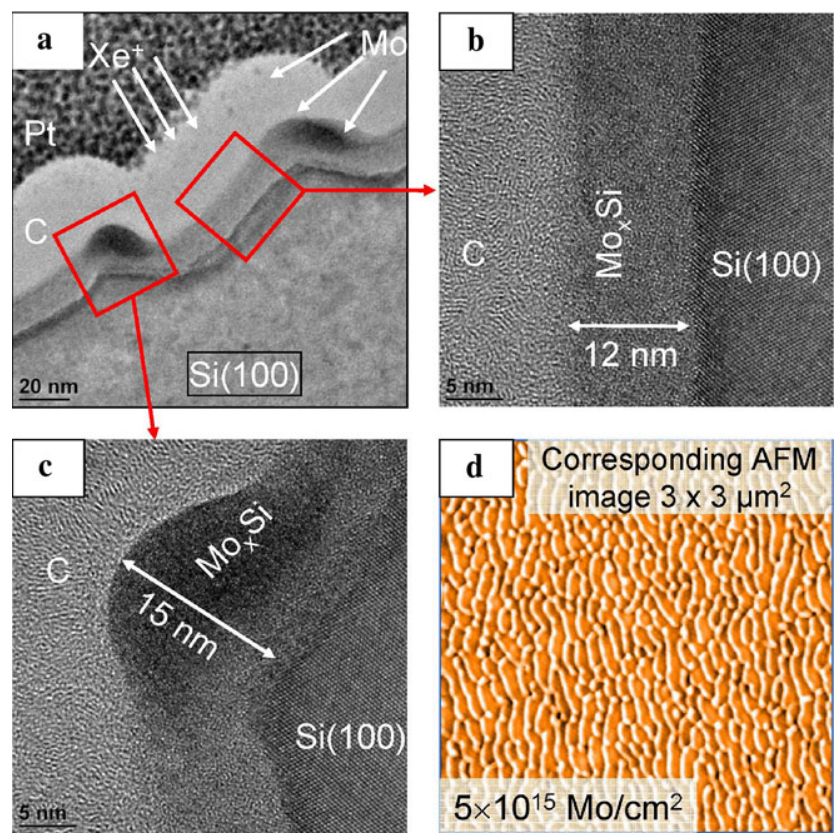

Fig. 3 High resolution TEM analysis of a ripple profile. (a) Cross section through two ripple ridges. Prior to TEM analysis, an amorphous carbon layer was deposited on the surface to ensure the contrast between the Mo-Si layer and the Pt-C glue. The ion and atom beam directions are indicated as arrows. (b) Zoom into the region between ripple ridges, showing a rather uniform amorphous Mo-Si layer. (c) Zoom into a ripple ridge. The amorphous layer reaches $15 \mathrm{~nm}$ in thickness and appears darker due to a higher Mo concentration. The width of the amorphous layer corresponds to the ion range. (d) AFM image of the sample region from which the TEM cross sections were prepared

Ion beam erosion with co-deposition of $\mathrm{Cu}$ or $\mathrm{Au}$ surfactant atoms does not produce surface patterns (Fig. 5). Even for a high coverage with $\mathrm{Cu}$ or $\mathrm{Au}$ atoms of $1.1 \times 10^{16}$ and $8.5 \times 10^{15}$ atoms $/ \mathrm{cm}^{2}$, respectively, the surface remains extremely flat with an rms roughness comparable to the nonirradiated substrates. In the case of $\mathrm{Cu}$, a weak irregular dot pattern starts to appear if the $\mathrm{Cu}$ coverage exceeds $1.4 \times 10^{16}$ atoms $/ \mathrm{cm}^{2}$.

The elemental depth distribution for the Si samples exposed to co-deposition of $\mathrm{Fe}, \mathrm{Mo}, \mathrm{Cu}$, and $\mathrm{Au}$ was analyzed with high resolution RBS. The results shown in Fig. 6 clearly reveal a metal containing surface layer with thickness of about $10 \mathrm{~nm}$ and a metal concentration reaching or even exceeding 20 at.\% for all samples. A residual Xe concentration of at most 3 at. $\%$ is also present. For the case of $\mathrm{Fe}$ and Mo, the concentration extends up to the surface and gradually decreases with increasing depth. On the other hand, the $\mathrm{Au}$ and $\mathrm{Cu}$ concentration profiles are rather uniform, but decrease toward the surface. $\mathrm{Cu}$ and $\mathrm{Au}$ seem to form buried $\mathrm{Me}_{x} \mathrm{Si}$ layers with a thin $\mathrm{Si}$ enriched surface as it was previously observed for Au surfactant sputtering of $\mathrm{Si}$ at oblique ion incidence [20]. The existence of such a steady-state buried $\mathrm{Me}_{x} \mathrm{Si}$ layer is evidence for strong ioninduced diffusion, because the steady-state surface coverage

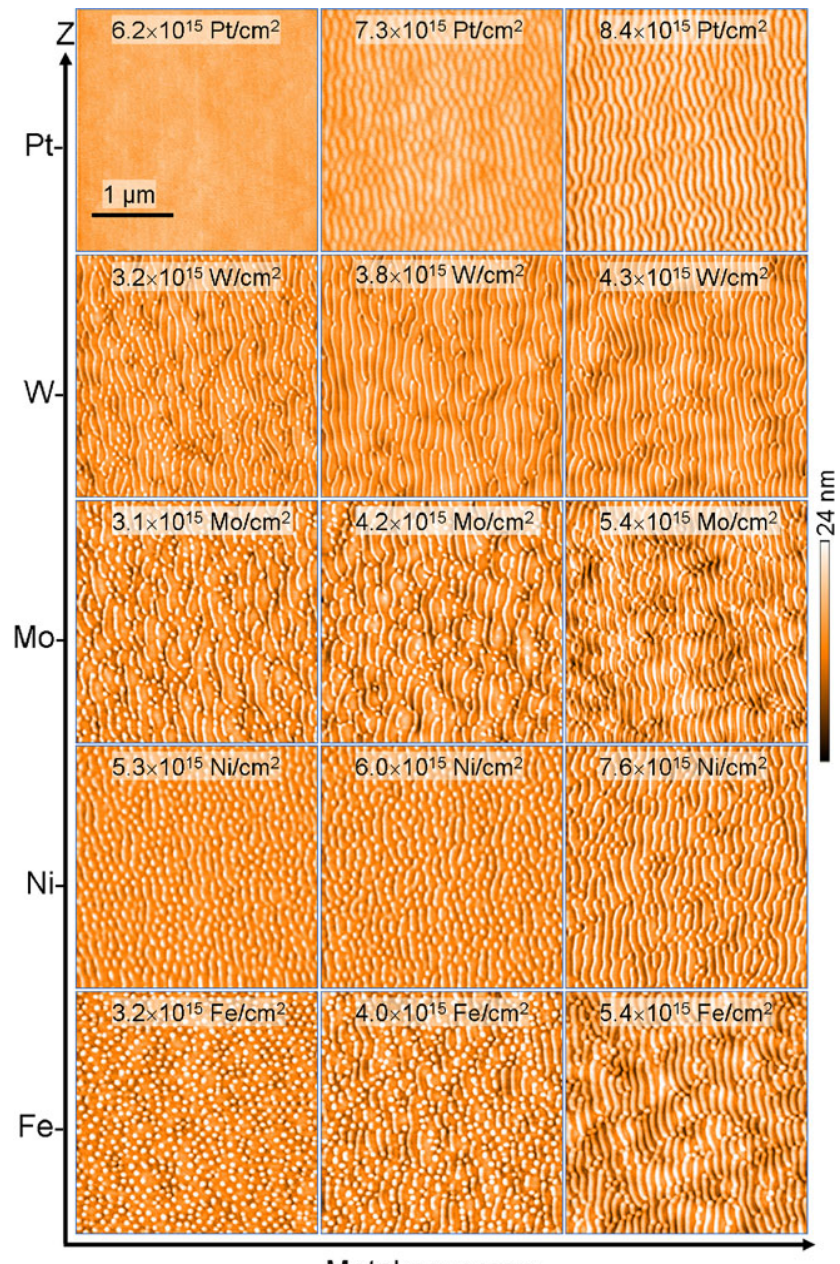

Metal coverage

Fig. 4 AFM topographic images of surfactant induced surface patterns on Si for different metal surfactant atoms $(\mathrm{Fe}, \mathrm{Ni}, \mathrm{Mo}, \mathrm{W}, \mathrm{Pt})$ and different metal surface coverage. The coverage in units of atoms $/ \mathrm{cm}^{2}$ was measured with RBS. Samples were irradiated with $5 \mathrm{keV}$ Xe ions with normal ion incidence at a fluence of $5 \times 10^{17} \mathrm{Xe} / \mathrm{cm}^{2}$ according to the setup shown in Fig. 1. The metal co-deposition occured from the left side of the shown images
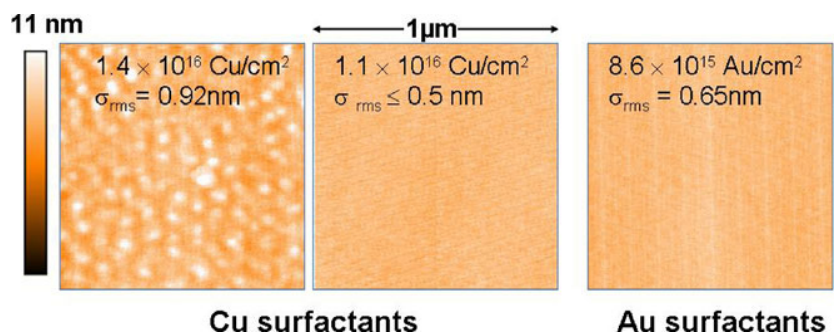

Fig. 5 AFM topographic images of a Si surface eroded $5 \mathrm{keV}$ Xe ions at room temperature and a fluence of $5 \times 10^{17} \mathrm{Xe} / \mathrm{cm}^{2}$ with $\mathrm{Cu}$ and $\mathrm{Au}$ surfactant atoms for high equilibrium surface coverage. Samples were irradiated according to the setup shown in Fig. 1

with $\mathrm{Si}$ requires continuous transport of $\mathrm{Si}$ atoms through the $\mathrm{Me}_{x} \mathrm{Si}$ layer. 

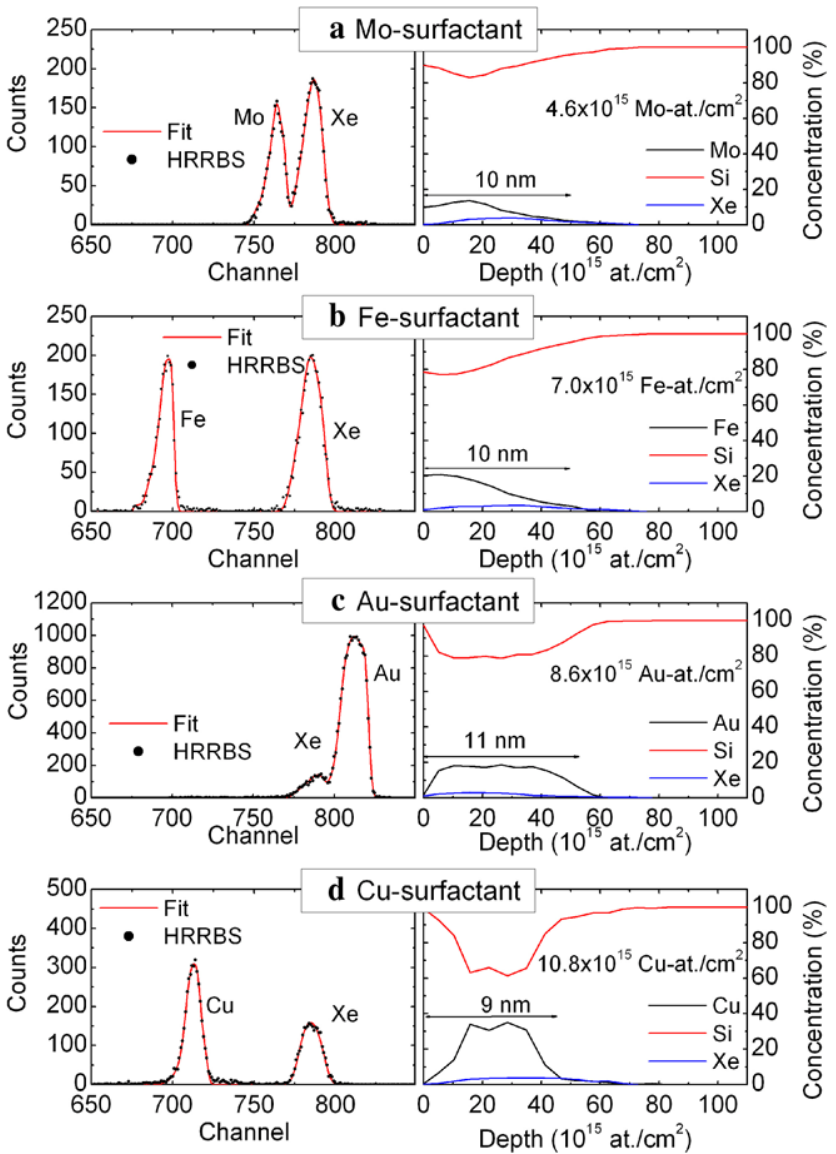

Fig. 6 Concentration-versus-depth profiles of co-deposited metal atoms measured with high resolution RBS. Left side: RBS spectra with fitted curves. Right side: Concentration profiles determined from the fit to the data. The fitted depth profiles and the elemental concentration profiles were obtained as described in [55]

Smoothing of a rough or rippled surface by ion irradiation at near normal incidence was already shown in several cases $[16,57]$. Here, we want to test, if normal incidence ion irradiation of $\mathrm{Si}$ and co-deposition of $\mathrm{Si}$ at oblique incidence (i.e., without any chemical effects) is able to maintain an existing pattern simply due to angle dependent sputtering, directed co-deposition and shadowing. For this test, we have prepared ripple patterns by gracing incidence $5 \mathrm{keV}$ Xe ion irradiation of pure Si and also using Mo co-deposition and perpendicular incident $5 \mathrm{keV}$ Xe ions. In the first case, a ripple pattern is generated after irradiation with $2 \times 10^{17} \mathrm{Xe} / \mathrm{cm}^{2}$ and $70^{\circ}$ incidence angle. This sample was then exposed to a perpendicular incident $5 \mathrm{keV} \mathrm{Xe}$ ion beam with oblique incident co-deposition of $\mathrm{Si}$. Already at a fluence of $5 \times 10^{16} \mathrm{Xe} / \mathrm{cm}^{2}$, the pattern has completely disappeared and a flat surface is obtained (Fig. 7). In the second case, the Mo sputter target was replaced by a Si target after the initial ripple pattern was generated and sputter erosion under oblique incidence co-deposition of $\mathrm{Si}$ was continued up to an ion fluence of $5 \times 10^{17} \mathrm{Xe} / \mathrm{cm}^{2}$. The AFM images

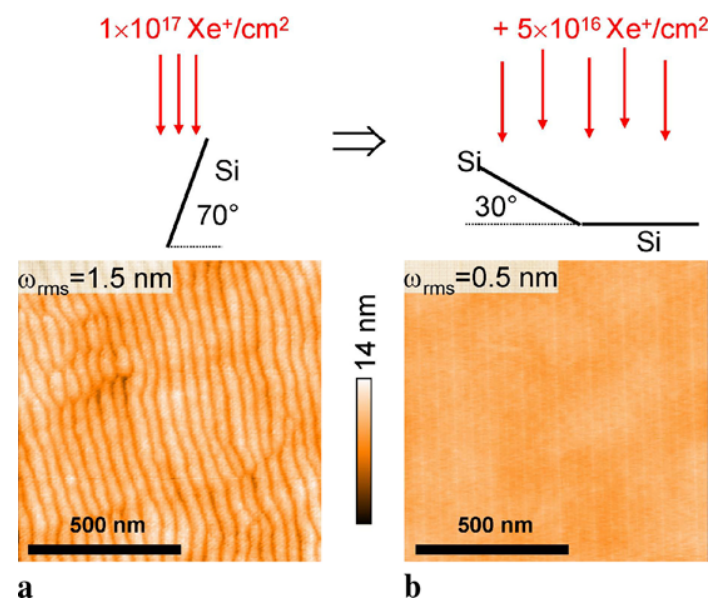

Fig. 7 (a) AFM image of a ripple pattern on $\mathrm{Si}$ generated by $5 \mathrm{keV}$ $\mathrm{Xe}$ ions incident at $70^{\circ}$. The ripple wave vector is oriented parallel to the projected ion beam direction. (b) AFM image of the Si surface after irradiating the initial ripple pattern with perpendicular incident $\mathrm{Xe}$ ions and co-deposition of $\mathrm{Si}$ at oblique incidence. The pattern disappears and a flat surface is obtained already for an ion fluence of $5 \times 10^{16} \mathrm{Xe} / \mathrm{cm}^{2}$

shown in Fig. 8 clearly show that the initial ripple pattern converts to a dot pattern, which slowly disappears. Eventually, the surface becomes flat. Due to sputter losses, the Mo coverage decreases from initially $5.5 \times 10^{15} \mathrm{Mo} / \mathrm{cm}^{2}$ to $0.5 \times 10^{15} \mathrm{Mo} / \mathrm{cm}^{2}$. The two tests confirm the important contribution of ion-induced diffusion and mass redistribution as smoothing mechanism in our experiments. This is in agreement with results in [16] obtained for similar experiments with normal ion incidence but without codeposition. To generate or maintain a certain dot or ripple pattern requires an efficient pattern formation process, which overrides smoothing by ion-induced diffusion.

\section{Discussion}

Ion-induced pattern formation described in this study has a number of characteristic features. First of all, irradiation at normal ion incidence excludes curvature dependent erosion (Bradley-Harper model [58]) and ion induced mass redistribution (Carter-Vishnyakov (CV) model [21]) as relevant pattern formation mechanism. Second, the irradiation at room temperature leads to dot and ripple patterns with several $\mathrm{nm}$ in amplitude and a wavelength of 100-150 nm. This is in contrast to high temperature irradiation, leading to micron size cone structures. Third, oblique co-deposition of self atoms like $\mathrm{Si}$ on $\mathrm{Si}$ is not able to generate or even maintain a dot or ripple structure. In this case, ion-induced diffusion or the $\mathrm{CV}$ effect act as efficient smoothing mechanism. Therefore, an even more efficient pattern formation mechanism is necessary to override smoothing. 


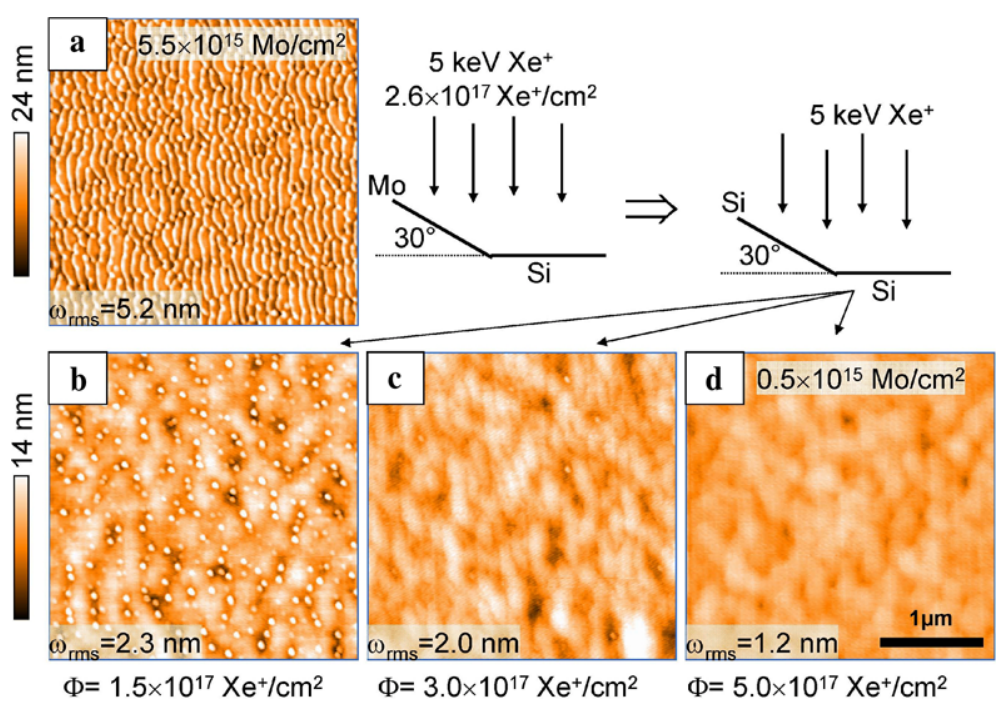

Fig. 8 AFM topographic images of surfactant induced surface patterns on $\mathrm{Si}$. (a) The initial ripple pattern was generated with $5 \mathrm{keV} \mathrm{Xe}$ ion irradiation with an ion fluence of $2.6 \times 10^{17} \mathrm{Xe} / \mathrm{cm}^{2}$ and perpendicular ion incidence and simultaneous co-deposition of Mo surfactants. The co-sputter target was then replaced by a Si target. Images (b)-(d) With increasing the ion fluence up to $5 \times 10^{17} \mathrm{Xe} / \mathrm{cm}^{2}$, the initial pattern

For the two surfactant species $\mathrm{Cu}$ and $\mathrm{Au}$, we do not find any pattern formation for normal ion incidence, except for $\mathrm{Cu}$ at very high coverage. $\mathrm{RBS}$ measurements reveal a mixed surface layer of several $\mathrm{nm}$ thickness with a $\mathrm{Cu}$ or $\mathrm{Au}$ concentration even exceeding 20 at. $\%$.

On the other hand, for $\mathrm{Fe}, \mathrm{Ni}, \mathrm{Mo}$, and $\mathrm{W}$ very pronounced dot and ripple patterns are formed already at rather low steady-state metal coverage. In the case of Pt as surfactant, a much larger coverage is required to obtain weak ripple patterns. In the cases where patterns are generated, the characteristic length scale (dot spacing or ripple wavelength) is similar and in the range $100-150 \mathrm{~nm}$. In previous erosion studies for Fe co-deposition on $\mathrm{Si}$ [2] and also for the case of Mo co-deposition on Si (Fig. 2), it is observed that with increasing ion fluence initially an irregular granular pattern or dot pattern is generated. For a given ion fluence and below a certain critical surfactant coverage, the surface remains flat. Above such a critical coverage, a dot pattern is formed and above a higher critical coverage a dot pattern evolves into a ripple pattern with increasing ion fluence [2, 4]. The pattern evolution shown in Fig. 4 indicates a similar behavior for $\mathrm{Ni}$ and $\mathrm{W}$ surfactants.

A flat steady-state Fe-silicon or Mo-silicon surface layer is formed, with spatially rather uniform metal concentration before the initial step toward a dot pattern set in (Fig. 2 and [2]). The layer thickness of several $\mathrm{nm}$ corresponds to the ion range of the incident ions. When patterns are formed, the ridges of the ripples and the regions of the dots show a highly enriched metal concentration, whereas the metal concentration in the region in between is very low (Fig. 3 and disappears and eventually a flat surface is obtained. The rms roughness $\omega_{\text {rms }}$ is indicated. After irradiation with $5 \times 10^{17} \mathrm{Xe} / \mathrm{cm}^{2}$, the Mo coverage has decreased due to sputtering by an order of magnitude. The metal and Si co-deposition occurred from the left side of the shown images

[2]). We also expect a similar behavior for $\mathrm{Ni}$ and $\mathrm{W}$ surfactants.

Pure collision cascade effects like sputtering, preferential sputtering, mass transport within the collision cascade, crater formation, etc. cannot explain the strong differences in the patterns observed for different surfactant atoms, in particular, if we compare (i) $\mathrm{Fe}$ and $\mathrm{Ni}$ with $\mathrm{Cu}$, or (ii) W and $\mathrm{Pt}$ with $\mathrm{Au}$ as surfactant atoms. The respective collision cascade related parameters like sputter yield, ion range, number of displacements, vacancy and recoil distribution, etc. are quite similar for the case of $\mathrm{Fe}, \mathrm{Ni}, \mathrm{Cu}$ surfactants and also for $\mathrm{W}, \mathrm{Pt}, \mathrm{Au}$ surfactants. In the absence of chemical effects, we would expect a very similar pattern formation behavior within the two groups $(\mathrm{Fe}, \mathrm{Ni}, \mathrm{Cu})$ and $(\mathrm{W}, \mathrm{Pt}, \mathrm{Au})$.

The recent model proposed by Bradley predicts pattern formation from normal ion incidence and oblique codeposition of atoms if there is preferential sputtering of substrate atoms [26]. In our experiments, the sputter yield for $\mathrm{Si}$ is always much smaller compared to the sputter yield for the metals considered. Therefore, the novel model of Bradley does not apply to our case.

In the following, we discuss the different experiments presented here with regard to chemical effects, in particular phase separation. As a first step, we calculate the average metal atomic concentration $c_{M}$ in this mixed surface layer from the measured metal coverage $\sigma_{M}$.

$c_{M}\left[\right.$ at. \%] $=100 \cdot \frac{1}{\frac{\rho_{S}}{\sigma_{M}} \cdot \frac{N_{A}}{A_{S}} \cdot d-\frac{\rho_{S} A_{M}}{\rho_{M} A_{S}}+1}$. 
Here, $\rho_{S}$ and $\rho_{M}$ are the mass densities of substrate and metal, $A_{S}$ und $A_{M}$ the respective molar weight, and $N_{A}$ is Avogadro's constant. The thickness $d$ of the mixed layers is calculated from the ion range for a given $\mathrm{Me}-\mathrm{Si}$ composition with the help of SDTrimSP simulations [51], assuming a solid solution with the respective elemental densities. We use approximately

$d \approx r_{P}+2 \sigma_{\mathrm{Str}}$

with projected ion range $r_{P}$ and longitudinal straggling $\sigma_{s t r}$. The values are in good agreement with the metal depth distributions obtained from HR-RBS (Fig. 6).

\section{$5 \mathrm{Cu}$ and Au surfactants}

For $\mathrm{Cu}$ and $\mathrm{Au}$ co-deposition, we find no pattern formation and the surface remains flat, except for a very high $\mathrm{Cu}$ coverage $\geq 1.4 \times 10^{16} \mathrm{Cu} / \mathrm{cm}^{2}$ (Fig. 4). Nevertheless, a mixed steady state $\mathrm{Cu}-\mathrm{Si}$ or $\mathrm{Au}-\mathrm{Si}$ surface layer with about $10 \mathrm{~nm}$ thickness is formed (Fig. 5). The thickness of the mixed surface layer is in good accordance with the respective projected ion ranges. For $\mathrm{Cu}-\mathrm{Si}$, there exist several stable $\mathrm{Cu}$ silicides with high $\mathrm{Cu}$ content in the $\mathrm{Cu}-\mathrm{Si}$ phase diagram. The silicide phase with highest $\mathrm{Cu}$ content of 76 at.\% is $\mathrm{Cu}_{19} \mathrm{Si}_{6}$. There is also a eutectic point at $803^{\circ} \mathrm{C}$ at composition $\mathrm{Cu}_{2} \mathrm{Si}$ [59]. For $\mathrm{Au}-\mathrm{Si}$, no stable silicides exist, but there is a eutectic point at rather low temperature of $370{ }^{\circ} \mathrm{C}$ with composition $\mathrm{Au}_{4} \mathrm{Si}$ [59]. In thermodynamic equilibrium, we would obtain a phase separation into $\mathrm{Si}$ and $\mathrm{Au}$ or $\mathrm{Si}$ and $\mathrm{Cu}$ silicide. During ion beam erosion of $\mathrm{Si}$ with weak co-deposition of $\mathrm{Cu}$ and $\mathrm{Au}$, we can expect a supersaturated mixture as result of recoil implantation and ion beam mixing at room temperature. In the case of $\mathrm{Cu}$, silicide formation may only occur if the $\mathrm{Cu}$ concentration becomes rather high. Indeed, ion induced $\mathrm{Cu}$ silicide formation has been observed by grazing incidence $\mathrm{x}$-ray diffraction after room temperature Ar ion irradiation of thin $\mathrm{Cu}$ films deposited on $\mathrm{Si}$ [60]. Au-Si alloy formation also occurs after room temperature $\mathrm{Ar}$ ion irradiation of thin $\mathrm{Au}$ films on $\mathrm{Si}$ [61]. A total mixing of an evaporated Au film on $\mathrm{Si}$ was observed for $200 \mathrm{keV} \mathrm{Kr}$ ion irradiation at room temperature with a fluence of $1 \times 10^{16} \mathrm{~cm}^{-2}$ [62], and also after $\mathrm{MeV}$ ion irradiation at room temperature [63]. In these studies, the mixing process starts with evaporated pure metal films, i.e., the highest possible metal concentration. In our case of ion beam irradiation and simultaneous metal co-deposition, the maximum concentration of metal atoms is rather low and we are approaching the steady state coverage state starting from pure $\mathrm{Si}$. According to HR-RBS, the maximum steady state $\mathrm{Au}$ or $\mathrm{Cu}$ concentration for coverage up to $10^{16}$ at. $/ \mathrm{cm}^{-2}$ reaches 20-30 at.\% (Fig. 6). Therefore, we obtain a steadystate amorphous $\mathrm{Cu}_{x} \mathrm{Si}$ and $\mathrm{Au}_{\mathrm{x}} \mathrm{Si}$ alloy phase with variable composition between $0 \leq x \leq 0.3$ in the case of $\mathrm{Cu}$ and $0 \leq x \leq 0.2$ in the case of $\mathrm{Au}$. The possibility to form a $\mathrm{Cu}$ silicide phase with stoichiometry approaching $\mathrm{Cu}_{2} \mathrm{Si}$ in this concentration regime is rather unlikely. Although small amounts of metal-rich clusters may form during individual ion impacts, these clusters will be effectively destroyed by subsequent incident ions. The equilibrium composition of the ion beam mixed surface layer remains uniform. Therefore, for the case of $\mathrm{Cu}-\mathrm{Si}$ and $\mathrm{Au}-\mathrm{Si}$, we expect a very weak tendency for phase separation, so that the surface remains flat. An onset of pattern formation is visible only in the case of a rather high $\mathrm{Cu}$ coverage $\geq 1.4 \times 10^{16} \mathrm{Cu} / \mathrm{cm}^{2}$ (Fig. 5). The maximum ion range from Eq. (2) in this case is $d \approx 9 \mathrm{~nm}$ and from Eq. (1) we calculate $c_{\mathrm{Cu}} \approx 28$ at. $\%$. For $1.1 \times 10^{16} \mathrm{Cu} / \mathrm{cm}^{2}$ or $c_{\mathrm{Cu}} \approx 22$ at.\% we still obtain a flat surface.

\section{Pt surfactants}

The complex Pt-Si phase diagram has several stable phases $\left(\mathrm{Pt}_{5} \mathrm{Si}_{2}, \mathrm{Pt}_{2} \mathrm{Si}\right.$, and $\left.\mathrm{PtSi}\right)$ and an eutectic point at $\mathrm{PtSi}_{2}$ and $979^{\circ} \mathrm{C}[59,64]$. The most stable silicides are $\mathrm{PtSi}$ and $\mathrm{Pt}_{2} \mathrm{Si}$ with melting point of $1200{ }^{\circ} \mathrm{C}$ and $1100{ }^{\circ} \mathrm{C}$ and formation enthalpies of $-59.6 \pm 2 \mathrm{~kJ} /$ mole and $-63 \pm 2 \mathrm{~kJ} / \mathrm{mole}$, respectively [65]. Ion assisted formation of Pt silicide was observed in hyperthermal pulsed cathodic arc deposition of PtSi layers [66]. During room temperature Pt deposition on Si with simultaneous $150 \mathrm{keV}$ Ar ion irradiation a linear dependence of the reacted $\mathrm{Pt}_{2} \mathrm{Si}$ layer with ion fluence was found. In this experiment, the onset of PtSi formation is at higher temperatures of $800 \mathrm{~K}$ [67]. Our results for co-deposition of $\mathrm{Pt}$ on Si during ion beam erosion show that patterns are formed only for a very high steady state Pt coverage with $\geq 7 \times 10^{15} \mathrm{Pt} / \mathrm{cm}^{2}$. For $d \approx 10 \mathrm{~nm}$, we obtain $\mathrm{c}_{\mathrm{Pt}} \geq 13$ at. $\%$. At such a high supersaturation with $\mathrm{Pt}$, a phase separation toward a PtSi stoichiometry could be initiated leading to a lateral inhomogeneous Pt concentration as steady-state. At lower Pt coverage, a phase separation will be weak, and we expect a similar behavior to $\mathrm{Cu}$ and $\mathrm{Au}$, i.e., no pattern formation (Fig. 4).

\section{$7 \mathrm{Fe}, \mathrm{Ni}, \mathrm{Mo}$, and W surfactants}

These surfactant atoms lead to very pronounced dot and ripple patterns with rather similar features like wavelength, ripple amplitude and ripple shape. The binary phase diagrams of these metals with Si exhibit certain similarities [59]. First, there is a stable silicon-rich silicide phase with composition $\mathrm{MeSi}_{2}$ with large negative heat of formation at room temperature between -80 and $-140 \mathrm{~kJ} / \mathrm{mol}[68,69]$. The heat of formation of Ni silicides is a little bit lower around 
$-45 \mathrm{~kJ} / \mathrm{mol}$ [70]. Second, there also exist other metal-rich stable silicide phases. Therefore, the Gibbs free energy has pronounced minima for these metal silicide compositions. The melting temperatures of silicides are rather high, starting at $1027^{\circ} \mathrm{C}$ for $\mathrm{Ni}-\mathrm{Si}, 1500^{\circ} \mathrm{C}$ for $\mathrm{Cu}-\mathrm{Si}$, and $>1700^{\circ} \mathrm{C}$ for $\mathrm{Mo}-\mathrm{Si}$ and $\mathrm{W}-\mathrm{Si}$. The $\mathrm{Fe}-\mathrm{Si}$ system forms $\mathrm{FeSi}$ and $\mathrm{FeSi}_{2}$ silicides upon annealing to $600-800^{\circ} \mathrm{C}$ [71-73]. Ion beam induced formation of silicide phases is known for all of these metals. Ion beam mixing of $\mathrm{Fe}-\mathrm{Si}$ bilayers promotes silicide formation at low temperatures $450-550{ }^{\circ} \mathrm{C}$ [74]. A similar behavior was found for the ion beam induced $\mathrm{WSi}_{2}$ formation starting from $\mathrm{W}-\mathrm{Si}$ multilayer films [75]. The formation of $\mathrm{Mo}_{3} \mathrm{Si}_{2}, \mathrm{MoSi}_{2}$, or $\mathrm{Ni}_{3} \mathrm{Si}_{2}$ silicides during ion sputtering induced cone formation was already mentioned in the Introduction [3, 14, 41]. Starting from Ni-Si bilayers, the ion induced formation of $\mathrm{Ni}_{2} \mathrm{Si}$ was observed after $>100 \mathrm{keV} \mathrm{Kr}$ ion irradiation [76, 77]. Metal silicides do not need to be crystalline. As already mentioned in the Introduction, amorphous semiconducting Fe disilicide can be grown, e.g., by sputter deposition. $\mathrm{Fe}-\mathrm{Si}$ bonds are identified via XPS measurements or electron diffraction [18, 44-49].

Based on this discussion, we interpret our results for $\mathrm{Fe}$, $\mathrm{Ni}, \mathrm{Mo}$, and $\mathrm{W}$ in the following way: During surfactant sputtering of $\mathrm{Si}$ with co-deposition of $\mathrm{Fe}, \mathrm{Ni}, \mathrm{Mo}$, and $\mathrm{W}$, a supersaturated metal-Si mixture is formed by ion mixing and ion-induced diffusion. In the initial stages at low ion fluences, the surface of the mixed layer is still flat, as can be seen from Fig. 2 for co-deposition of Mo and from [2] for co-deposition of Fe. With increasing ion fluence, the mixture tends to phase separate toward an amorphous metal disilicide phase and an amorphous Si phase with low metal content. As a consequence, a lateral inhomogeneous distribution of metal atoms arises, with regions approaching a disilicide stoichiometry. As outlined in our previous work on Fe surfactant triggered pattern formation by ion beam erosion of $\mathrm{Si}$ [2], the spatial phase separation causes slightly different composition dependent erosion rates (preferential sputtering as well as sputter yield amplification). Such a difference is sufficient to generate initially an irregular dot pattern with increasing dot height (Fig. 2 and [2]). At least for Fe and Mo surfactants, we have shown that the dots contain a higher metal concentration, the regions in between a low metal concentration. Due to phase separation, an ion induced net diffusion current of metal atoms to regions of higher metal concentration is generated and eventually an equilibrium between feeding these regions on the one hand and loss due to sputter erosion and ion beam mixing on the other hand will be established. For Fe and Mo surfactants and $5 \mathrm{keV} \mathrm{Xe}$ ion irradiation with fluence of $5 \times 10^{17} \mathrm{Xe} / \mathrm{cm}^{2}$ pattern formation sets in at about $2-3 \times 10^{15}$ at. $/ \mathrm{cm}^{2}$, corresponding to a metal concentration of only about $c_{\mathrm{Fe}} \approx c_{\mathrm{Mo}} \approx 3$ at.\% within a $13 \mathrm{~nm}$ thick surface layer. The strong tendency for pattern formation in these four systems is attributed to the existence of rather stable (amorphous) disilicide phases. These silicides seem to be preferably formed compared to pure metal clusters.

If the metal concentration approaches or exceeds 33 at. $\%$, corresponding to the disilicide stoichiometry, there will be no longer a chemical driving force for phase separation. In this case, the surface should remain flat. Indeed, we observe a spatially rather sharp transition from pronounced ripple patterns with high amplitude to a very flat surface for the case of Fe co-deposition onto $\mathrm{Si}$ during $5 \mathrm{keV}$ Xe sputter erosion at $30^{\circ}$ ion incidence [18]. In this transition region, the $\mathrm{Fe}$ coverage is $1.7-1.8 \times 10^{16} \mathrm{Fe} / \mathrm{cm}^{2}$, corresponding to a $\mathrm{Fe}$ concentration of about 33 at.\% in the amorphous $\mathrm{Fe}_{x} \mathrm{Si}$ surface layer with thickness $d \approx 8-9 \mathrm{~nm}$. A very similar sharp transition was found by Macko et al. for $1 \mathrm{keV} \mathrm{Ar}$ ion irradiation at $30^{\circ}$ and $\mathrm{Fe}$ co-deposition [4].

\section{Conclusion}

In this work, we have extended our previous studies [2, 18] on Fe surfactant induced pattern formation on Si during normal and near normal incidence ion irradiation to a number of different co-deposited metal atoms. The evolution of ripple patterns as function of steady-state Fe coverage, and in particular the sharp transition from ripples to a flat surface when the $\mathrm{Fe}$ coverage reaches the $\mathrm{FeSi}_{2}$ stoichiometry were strong arguments for the role of silicide formation in the $\mathrm{Fe}-$ $\mathrm{Si}$ system [18]. In order to generalize the validity of our previously introduced pattern formation scenario based on initial chemical effects and phase separation toward silicide phases, the metal atoms in the present study were selected according to their ability to form metal silicides. We have shown that ion beam erosion of $\mathrm{Si}$ at room temperature with ions incident at normal direction and simultaneous oblique angle co-deposition of different metal surfactant atoms results in significantly different surface topographies, dependent on the surfactant species and the surfactant steady state coverage. The strongly different pattern formation behavior within two groups of surfactants, i.e., $(\mathrm{Fe}, \mathrm{Ni}, \mathrm{Cu})$ and (W, $\mathrm{Pt}, \mathrm{Au}$ ), rules out processes which are solely determined by collision effects. Furthermore, because of perpendicular ion incidence, curvature dependent erosion [58] and mass redistribution [21] cannot account for pattern formation.

Our results obtained for the different metallic surfactant atoms confirm our previously presented scenario of pattern formation based on ion-induced phase separation and composition dependent sputtering. The most pronounced tendency for pattern formation exists for the metals $\mathrm{Fe}, \mathrm{Ni}$, Mo, and W, forming Si-rich (amorphous) silicides with stoichiometry $\mathrm{MeSi}_{2}$. An average steady-state metal concentration in the surface layer of only 3 at.\% is sufficient to trigger ion-induced pattern formation. For Pt surfactants, the 
observed tendency for phase separation is weaker and the resulting sinusoidal ripple patterns require a much higher Pt coverage with Pt concentration in the surface layer of at least 13 at.\%. We attribute the less pronounced pattern formation to the fact that no disilicide but a stable monosilicide with PtSi composition exists. Metal surfactants for which only metal-rich silicides exist $(\mathrm{Cu}, \mathrm{Pt})$, or where no stable silicide phase exists $\mathrm{(Au})$ will generate no or only weak patterns on $\mathrm{Si}$. In these cases, the steady-state $\mathrm{Cu}_{x} \mathrm{Si}$ and $\mathrm{Au}_{x} \mathrm{Si}$ alloy surface layer maintains a lateral uniform composition and remains flat for a wide range of metal coverage and ion fluence.

Oblique incidence co-deposition without a chemical driving force was tested for co-deposition of $\mathrm{Si}$ on patterned $\mathrm{Si}$ surfaces at room temperature. We find that it is not possible to maintain an initially existing surface pattern based on geometrical effects like directed deposition, shadowing, and local angle dependent sputtering. Ion induced diffusion and also the $\mathrm{CV}$ effect is seen as the major contribution leading to smooth surfaces.

Based on our results for $\mathrm{Fe}, \mathrm{Ni}, \mathrm{Mo}$, and $\mathrm{W}$ and based on binary compound phase diagrams [59], we predict pronounced ion-induced pattern formation to occur in several other similar systems for perpendicular ion irradiation and metal co-deposition. We suggest to study $\mathrm{Cr}$, Ti, $\mathrm{Zr}$, Ta, $\mathrm{V}, \mathrm{Y}$ as surfactant atoms on $\mathrm{Si}$. These metals form stable disilicides. For carbon as a substrate (amorphous carbon or graphite) pronounced patterns should arise for $\mathrm{Nb}, \mathrm{Mo}$, and $\mathrm{Hf}$ surfactants, all of them form stable $\mathrm{MeC}_{2}$ phases. Flat surfaces are predicted for $\mathrm{B}, \mathrm{Sn}, \mathrm{Ge}$, and $\mathrm{Al}$ surfactants on $\mathrm{Si}$. A weak pattern formation similar to the case $\mathrm{Pt}-\mathrm{Si}$ is predicted for $\mathrm{W}, \mathrm{Ti}, \mathrm{V}$ on $\mathrm{C}$ and for the $\mathrm{Si}-\mathrm{C}$ system.

Acknowledgements This work was funded by the Deutsche Forschungsgemeinschaft under contract HO1125/20-1,2. We like to thank R.M. Bradley, K.H. Heinig, R. Kree, and U. Krebs for valuable discussions and comments.

Open Access This article is distributed under the terms of the Creative Commons Attribution License which permits any use, distribution, and reproduction in any medium, provided the original author(s) and the source are credited.

\section{References}

1. H. Hofsäss, K. Zhang, Appl. Phys. A 92, 517 (2008)

2. K. Zhang, M. Brötzmann, H. Hofsäss, New J. Phys. 13, 013033 (2011)

3. S. Macko, F. Frost, B. Ziberi, D. Förster, T. Michely, Nanotechnology 21, 085301 (2010)

4. S. Macko, F. Frost, M. Engler, D. Hirsch, T. Höche, J. Grenzer, T. Michely, New J. Phys. 13, 073017 (2011)

5. M. Cornejo, B. Ziberi, C. Meinecke, D. Hirsch, J.W. Gerlach, Th. Höche, F. Frost, B. Rauschenbach, Appl. Phys. A 102, 593 (2011)

6. J.A. Sánchéz-García, L. Vázquez, R. Gago, A. Redondo-Cubero, J.M. Albella, Z. Czigány, Nanotechnology 19, 355306 (2008)
7. J. Zhou, S. Facsko, M. Lu, W. Möller, J. Appl. Phys. 109, 104315 (2011)

8. M. Cornejo, B. Ziberi, C. Meinecke, F. Frost, Appl. Surf. Sci. 257, 8659 (2011)

9. A. Keller, S. Facsko, Materials 3, 4811 (2010)

10. J. Punzel, W. Hauffe, Phys. Status Solidi A 14, K97 (1972)

11. G.K. Wehner, J. Vac. Sci. Technol. A 3, 1821 (1985)

12. A.K. Sen, D. Ghose, J. Mat. Sci. Lett. 10, 1304 (1991)

13. M. Morishita, F. Okuyama, J. Vac. Sci. Technol. A 8, 3295 (1990)

14. N.G. Shang, F.Y. Meng, F.C.K. Au, Q. Li, C.S. Lee, I. Bello, S.T. Lee, Adv. Mater. 14, 1308 (2002)

15. M. Tanemura, T. Okita, J. Tanaka, H. Yamauchi, L. Miao, S. Tanemura, R. Morishima, Eur. Phys. J. D 34, 283 (2005)

16. G. Ozaydin-Ince, K.F. Ludwig Jr., J. Phys. Condens. Matter 21, 224008 (2009)

17. S. Macko, J. Grenzer, F. Frost, M. Engler, D. Hirsch, M. Fritzsche, A. Mücklich, Th. Michely, New J. Phys. 14, 073003 (2012)

18. H. Hofsäss, M. Brötzmann, K. Zhang, AIP Adv. 2, 032123 (2012)

19. K. Zhang, H. Hofsäss, H. Zutz, Nucl. Instrum. Methods B 286, 2010 (1967)

20. H. Hofsäss, K. Zhang, Nucl. Instrum. Methods B 267, 2731 (2009)

21. G. Carter, V. Vishnyakov, Phys. Rev. B 54, 17647 (1996)

22. C.S. Madi, E. Anzenberg, K.F. Ludwig Jr., M.J. Aziz, Phys. Rev. Lett. 106, 066101 (2011)

23. R. Kree, T. Yasseri, A.K. Hartmann, Nucl. Instrum. Methods B 267, 1403 (2009)

24. A.K. Hartmann, R. Kree, T. Yasseri, J. Phys. Condens. Matter 21, 224015 (2009)

25. R.M. Bradley, Phys. Rev. B 83, 195410 (2011)

26. R.M. Bradley, Phys. Rev. B 85, 115419 (2012)

27. I. Gerhards, H. Stillrich, C. Ronning, H. Hofsäss, M. Seibt, Phys. Rev. B 70, 245418 (2004)

28. G. Abrasonis, G.J. Kovács, M.D. Tucker, R. Heller, M. Krause et al., Appl. Phys. Lett. 97, 163108 (2010)

29. C.Q. Chen, Y.T. Pei, K.P. Shaha, J.Th.M. De Hosson, Appl. Phys. Lett. 96, 073103 (2010)

30. S.W. Chee, B. Stumphy, N.Q. Vo, R.S. Averback, P. Bellon, Acta Mater. 58, 4088 (2010)

31. K.P. Tai, X.D. Dai, B.X. Liu, Appl. Phys. Lett. 88, 184103 (2006)

32. P. Krasnochtchekov, R.S. Averback, P. Bellon, Phys. Rev. B 72, 174102 (2005)

33. K.H. Heinig, T. Müller, B. Schmidt, M. Strobel, W. Möller, Appl. Phys. A 77, 17 (2003)

34. S. Bera, B. Satpati, D.K. Goswami et al., J. Appl. Phys. 99, 074301 (2006)

35. P.E. Hovsepian, Y.N. Kok, A.P. Ehiasarian et al., Surf. Coat. Technol. 200, 1572 (2005)

36. Y. Batra, D. Kabiraj, S. Kumar, D. Kanjilal, J. Phys. D: Appl. Phys. 40, 4568 (2007)

37. R.A. Enrique, P. Bellon, Phys. Rev. B 63, 134111 (2001)

38. P. Krasnochtchekov, R.S. Averback, P. Bellon, Phys. Rev. B 75, 144107 (2007)

39. S.A. Khan, K.-H. Heinig, D.K. Avasthi, J. Appl. Phys. 109, $094312(2011)$

40. N.G. Shang, X.L. Ma, C.P. Liu, I. Bello, S.T. Lee, Phys. Status Solidi A 207, 309 (2010)

41. X.L. Ma, N.G. Shang, Q. Li, C.S. Lee, I. Bello, S.T. Lee, J. Cryst. Growth 234, 654 (2002)

42. J.H. Wu, R.S. Goldman, Appl. Phys. Lett. 100, 053103 (2012)

43. S. Le Roy, E. Barthel, N. Brun, A. Lelarge, E. Søndergård, J. Appl. Phys. 106, 094308 (2009)

44. L. Antwis, R. Gwilliam, A. Smith, K. Homewood, C. Jeynes, Semicond. Sci. Technol. 27, 035016 (2012)

45. M. Milosavljevic, G. Shao, N. Bibic, C.N. McKinty, C. Jeynes, K.P. Homewood, Nucl. Instrum. Methods B 188, 166 (2002) 
46. T. Yoshitake, M. Yatabe, M. Itakura, N. Kuwano, Y. Tomokiyo, K. Nagayama, Appl. Phys. Lett. 83, 3057 (2003)

47. M. Naito, M. Ishimaru, Y. Hirotsu, J.A. Valdez, K.E. Sickafus, Appl. Phys. Lett. 87, 241905 (2005)

48. M. Nikolaeva, M. Sendova-Vassileva, D. Dimova-Malinovska, D. Karpuzov, J.C. Pivinc, G. Beshkov, Vacuum 69, 221 (2003)

49. B. Egert, G. Panzner, Phys. Rev. B 29, 2091 (1984)

50. S. Habenicht, W. Bolse, K.-P. Lieb, Rev. Sci. Instrum. 69, 2120 (1998)

51. W. Eckstein, R. Dohmen, A. Mutzke, R. Schneider, Max-Planck Institute for Plasma Physics, IPP Report 12/3 (2007)

52. S. Berg, I. Katardjiev, Surf. Coat. Technol. 84, 353 (1996)

53. http://www.gwyddion.net

54. M. Uhrmacher, H. Hofsäss, Nucl. Instrum. Methods B 240, 48 (2005)

55. C. Borschel, M. Schnell, C. Ronning, H. Hofsass, Nucl. Instrum. Methods B 267, 1737 (2009)

56. H. Hofsäss, H. Binder, T. Klumpp, E. Recknagel, Diam. Relat. Mater. 3, 137 (1994)

57. F. Forst, R. Fechner, D. Flamm, B. Ziberi, W. Frank, A. Schindler, Appl. Phys. A 78, 651-654 (2004)

58. R.M. Bradley, J.M.E. Harper, J. Vac. Sci. Technol. A 6, 2390 (1988)

59. $\mathrm{F}^{*} \mathrm{~A} * \mathrm{C} * \mathrm{~T}$, Facility for the analysis of chemical thermodynamics, Centre de Recherche en Calcul Thermochimique, École Polytechnique, Université de Montréal. http://www.crct.polymtl.ca/fact/

60. D.K. Sarkar, S. Dhara, K.G.M. Nair, S. Chowdhury, Nucl. Instrum. Methods B 161-163, 992 (2000)

61. D.K. Sarkar, S. Dhara, A. Gupta, K.G.M. Nair, S. Chowdhury, Nucl. Instrum. Methods B 168, 21 (2000)
62. R. Khalfaoui, C. Benazzouz, A. Guittoum, N. Tabet, S. Tobbeche, Vacuum 81, 45 (2006)

63. S. Kumar, P.K. Sahoo, R.S. Chauhan, D. Kabiraj, U. Tiwari, D. Varma, D.K. Avasthi. Nucl. Instrum. Methods B 212, 238 (2003)

64. L.L. Xu, J. Wang, H.S. Liu, Z.P. Jin, Calphad 32, 101 (2008)

65. S.V. Meschel, O.J. Kleppa, J. Alloys Compd. 280, 231 (1998)

66. P.D. Swift, D.M. Ssolina, R.W. Cheary, G.M. McCredie, Thin Solid Films 440, 117 (2003)

67. S. Tamulevicius, L. Pranevicius, J. Budinavicius, Appl. Surf. Sci. 53, 159 (1991)

68. J. Acker, K. Bohmhammel, G.J.K. van den Berg, J.C. van Miltenburg, Ch. Kloc, J. Chem. Thermodyn. 31, 1523 (1999)

69. M.S. Chandrasekharaiah, J.L. Margrave, P.A.G. O'hare, J. Phys. Chem. Ref. Data 22, 1459 (1993)

70. R.K. Kummamuru, L. de la Rama, L. Hu, M.D. Vaudin, M.Y. Efremov, M.L. Green, D.A. Lavan, L.H. Allen, Appl. Phys. Lett. 95, 181911 (2009)

71. V.V. Balashev, V.V. Korobtsov, T.A. Pisarenko, E.A. Chusovitin, K.N. Galkin, Phys. Solid State 52, 397 (2010)

72. C. Lal, R. Dhunna, I.P. Jain, Mater. Sci. Semicond. Process. 11, 1 (2008)

73. R. Ayache, A. Bouabellou, F. Eichhorn, E. Richter, Rev. Adv. Mater. Sci. 8, 97 (2004)

74. M. Milosavljevic, S. Dhar, P. Schaaf, N. Bibic, M. Han, K.P. Lieb, Appl. Phys. A, Mater. Sci. Process. 71, 43 (2000)

75. G. Gawlik, J. Jagielski, Vacuum 83, S111 (2009)

76. N. Boussaa, A. Guittoum, S. Tobbeche, Vacuum 77, 125 (2005)

77. D. Datta, S.R. Bhattacharyya, Nucl. Instrum. Methods B 256, 248 (2007) 